\title{
Constellation of risk factors of the reproductive potential of youth
}

\author{
S.I. Filippchenkova ${ }^{1, *}$, E.A. Evstifeeva $^{2}$, I.I. Stolnikova ${ }^{3}$ \\ ${ }^{1}$ Doctor of Psychological sciences, Tver State Medical University, 4 Sovetskaya street, 170100, Tver, Russia. \\ ${ }^{2}$ Doctor of Philosophy, Tver State Medical University, 4 Sovetskaya street, 170100, Tver, Russia. \\ ${ }^{3}$ Candidate of Medical Sciences, Tver State Medical University, 4 Sovetskaya street, 170100, Tver, Russia.
}

\begin{abstract}
The concept of reproduction as a value-semantic formation, a natural biological process, a bloodrelated nature, and a psychological responsibility for preserving the genus is transforming in modern youth. Youth perceptions of life quality, demographic projections, levels of claims, degrees of satisfaction with life situations, and behavioral patterns are influenced by such psychological predictors as responsibility, reflexivity, value-semantic matrix, personal risk factors of decision making. The following issues were analyzed: sexual behavior, reproductive behavior, reproductive attitudes, reproductive function risks, attribution of responsibility, contraception, bad habits, sexually transmitted infections, caring for health in general and reproductive health in particular, needs for specialists in the field of sexual and reproductive health, demographic expectations of young people, awareness of the federal demographic policy and psychological support, social institutions aimed to preserve reproductive health, gender differences in the demographics of expectations. Attitudes of young people to sexuality and reproduction, family-marriage relations were studied. Sources of information on these issues were determined and their effectiveness was evaluated. Identification of features of the relationship between reproductive health and psychological characteristics of youth was embedded in the authors' psychological model.
\end{abstract}

\section{Introduction}

The understanding of reproduction as a value-semantic formation, a natural biological process, a blood-related feature, a personal and psychological responsibility for the preservation of the genus is transforming in modern youth. Youth perceptions of quality of life related to health, demographic projections, claims, satisfaction with life, and behavioral patterns are influenced by such psychological variables as responsibility, reflectivity, value-semantic matrices, and personal risk-factors of decision-making. Identification of features of the relationship between reproductive health and psychological characteristics of youth was embedded in the authors' psychological model.

\section{Problem Statement}

The following semantic blocks were analyzed: sexual behavior, reproductive behavior, reproductive attitudes, reproductive function risks, attribution of responsibility, contraception, bad habits, sexually transmitted infections, caring for health in general and reproductive health in particular, needs for specialists in the field of sexual and reproductive health, demographic expectations of young people, awareness of the state demographic policy and psychological support in the reproductive sphere, estimation of social institutions created to preserve reproductive health, gender differences in the demographics of expectations. Attitudes of young people to sexuality and reproduction, family-marriage relations were studied.

\section{Research Questions}

We will reveal the substantive side of basic concepts of the project - the psychological model of managing risk factors and quality of life associated with reproductive health, responsibility, and reflexivity. The psychological model of managing risk factors and quality of life associated with reproductive health is a psychometric tool used for describing, explaining and summarizing psychological and medical data on the quality of life and reproductive health of young people (Filippchenkova, 2013). The model focuses on personal parameters of quality of life associated with reproductive health, personality and psychological characteristics (responsibility, reflectivity, value-semantic preferences, personal risk factors of decision-making) of a young person who determines his risk, responsibility for his own well-being in terms of his health. The model will contribute to the development of a more general model of psychological support for safety in preserving reproduction (Sorokina et al., 2013). A complementary medical psychological model for managing quality of life related to reproductive health reveals a possibility of using the latest psychodiagnostic methods to assess the reproductive health. The methods can be used by 
psychologists and medical workers. The model can be used to design and test a training algorithm and medical and psychological consultations in the field of reproductive health.

Scientific knowledge about "health" remains problematic; "health" is viewed as an open and updated concept. A review of the health indicates the search for a holistic picture of health (Shamshurin, Shamshurina, 2018). From this perspective, a "navigational" understanding of health allows us to see psychological and personal efforts of the individual to preserve and improve it. The navigational aspect of health is a state of well-being of a person focused on key indicators of life quality, self-reproduction of his own identity (I. Kant). An organic unity of health and quality of life can be found in solving the problem of health quality management (Novik, 2000).

Health-related quality of life is a fragment of QL as a comprehensive assessment of all spheres of human life and society (Novik, Ionova, 2007; Novik et al., 2000; Zarakovsky (2009); Lebedeva, 2012). It is measured using objective and subjective approaches. (Belinskaya, Savinkina, 2018). The subjective component of wellbeing is a point of view of the person (Grishina, 2016). Given the complementarity of objective and subjective aspects of human well-being, their dialectics in the context of medical and psychological risks that accompany health, it is possible to create an image of health-related quality of life as a humanistic concept (Evstifeeva, Murashova, 2017).

Today, the risk is an attributive characteristic of social reality, a way of being. E. Giddens associates a risk with a dynamic mobilizing force which seeks all sorts of changes and desires to influence and determine its future (Giddens, 2004). A broad interpretation of the risk indicates the source of its origin, the generic relationship with uncertainty. The risk is any activity in the face of uncertainty. It is possible either to overcome it through minimization, or focus on its maximization. In our project, the risk is considered as a reproductive behavior of youth associated with uncertainty of outcomes - negative consequences for the reproduction. In terms of epistemological uncertainty, we distinguish between insufficient information about medical, sociopsychological, and economic consequences of abortion, a variety of hormonal therapy, pregnancy, assisted reproductive technologies (surrogacy, in vitro fertilization), dangers and consequences of smoking, drugs, alcohol for the reproductive function, a variety of sexually transmitted diseases. This cognitive uncertainty as a low level of human reflexivity can increase the risk space for the reproduction. The reduction of axiological uncertainty indicates such a habitus and value priorities as health and quality of life, including health-related quality of life.

The phenomenon of responsibility is an opportunity, ability, human competence. Responsibility is practical creation of oneself expressed in such functions as control, forecast, self-government. According to the logic of personal constitution, responsibility is a product of a choice made. In axiological projection, responsibility is seen as a focus and willingness to bear responsibility for own actions. The responsibility risk is a constructive position initiated by subjective-personal experience, which allows one to be steady, stable, predictable in relation to the uncertainty. The responsibility risk indicates ways to protect oneself from the effects of uncertainty. The risk of responsibility is a subjective, cognitive and personal ability to adequately respond to risks of loss of the reproductive function.

A willingness to accept responsibility for one's own well-being in the pro-creation sphere presupposes that youth have such formed personal and subjective qualities as responsibility, reflexivity, value-semantic preferences, and personal risk factors for decision-making. Their synergistic effect initiates a responsible position for reproductive health. Lack of ability to recognize accompanying reproductive health risks entails the desire to shift it to the external force (surrogacy, in vitro fertilization, or the institution of foster parenting and non-traditional partnerships).

Reflection is a feeling caused by authenticity, selfdetermination, and personal autonomy (Petrovsky, 2008). It is based on the moment of withdrawal of "I". Reflection is correlated with the self-denial. Reflexivity is a cognitive ability to introspection and criticism. Critical self-awareness is generated to exercise control over internal or self-experience (Lepsky, 2013).

Reorientation to the internal state entails a redesignation of the external environment, which mobilizes the subjective, cognitive and personal potential to solve any problem. There is a reflexive system for a person. A high degree of reflexivity allows us to realistically and adequately respond and accept the situation. Maintaining a high level of reflexivity helps manage reproductive health, mobilize psychological resources to overcome health-related obstacles. The "measure" of reflexivity, responsibility and other subjective, cognitive and personal characteristics of the perception of reproductive health risks, can change subjective indicators of health-related quality of life

\section{Purpose of the Study}

The study "Youth Reproductive Potential: Risks of Responsibility and Managing Quality of Health-related Life" is being carried out. It aims to analyze risk factors affecting the reproductive potential of young people to build a psychological model for managing quality of life related to reproductive health. The quality of life related to reproductive health is a projected variable influenced by mood, expectations, value preferences, personal and psychological characteristics.

To achieve the goal, the following tasks were set: using the author's questionnaire tested, to conduct a socio-psychological study aimed to identify attitudes to reproductive health, assess its level, and distinguish values of key behavioral risks in the field of sexuality and reproduction; to identify the relationship of subjective QL indicators related to health and psychological characteristics that affect them (responsibility, reflexivity, value-semantic preferences, personal risk factors of decision-making); to compare the 
dynamics of QL indicators related to health in students for 2013-2020; taking into account responsibility, reflectivity, value-semantic preferences, personal risk factors of decision-making, to develop a psychological model for managing risk factors and quality of life related to reproductive health; in the projection of risk factors, to develop a psychocorrectional technique for encouraging a healthy lifestyle. A comparative analysis of the dynamics of QL indicators related to the health of students in 2013-2020 was carried out taking into account responsibility, reflexivity, value-semantic preferences, and personal risk factors of decisionmaking. Based on the theoretical and empirical data, a psychological model for managing risk factors and quality of life related to reproductive health was developed. In the projection of risk factors related to reproductive health, a psycho-correctional technique for encouraging a healthy lifestyle will be developed and tested on students of Tver universities

\section{Research Methods}

The methodological basis is post-non-classical scientific rationality, an interdisciplinary approach, the concept of personalized medicine. Health-related quality of life is a complex concept revealed in its interdisciplinary content as an objective and subjective expression of the existential state of a person, his medical (physical) and psychological health.

\section{Findings}

An empirical study is conducted using a representative sample of 600 students of Tver universities. The research base is the psychodiagnostics laboratory of the Department of Psychology and Philosophy of Tver State Technical University, the psychodiagnostic laboratory of life quality and personal potential of Tver State Medical University. The routine examination was conducted in the Regional Clinical Hospital. The quality of life was studied using the questionnaire SF -36; psychological realities that affect decision making were studied using the methods developed by A.V. Karpov for the reflexivity level (Karpov, 2003), the method for diagnosing the level of subjective control developed by J. Rotter, the method developed by D.A. Leontiev, the method diagnosis for personality decision-making factors developed by T.P. Kornilova (Gusev, 2011; Kornilova, 2010). The data obtained were processed using the SPSS computer program. The research database was created.

The study of attitudes to reproductive health was conducted using a questionnaire, materials on various aspects of reproductive behavior and demographic expectations of young people. A sociological study was carried out using the author's questionnaire. The purpose of the questionnaire is to identify the reflection of reproductive health risks and the explication of key demographic projections of Russian youth. A sociological survey is aimed at analyzing demographic projections of students to justify a holistic view of conditions for causes and manifestations of behavioral risks of reproductive health of young people and creation of a program for formation of a healthy lifestyle in students. The quality of sociological data is ensured by the results of psychological diagnostics obtained using standardized and valid psychodiagnostic and mathematical-statistical methods. The research subject is knowledge on issues of sexual relations and risks of the reproductive function, attitudes to reproductive health, behavioral reproductive patterns, attribution of responsibility and demographic projections in students of Tver universities

\section{Conclusion}

Demographic instability of Russian society creates a problem field for scientific, medical and multidisciplinary research on the boundaries and facets of reproductive health of modern youth. Attitudes to reproductive health are formed in the projection of value preferences that young people choose. As numerous studies show, Russian young people do not learn the ethics of responsibility for "their well-being", shift it to modern medical technologies.

The study was financially supported by the Russian Fund of Fundamental Research Federal as part of project No. 19-01300188 "Reproductive potential of youth: risks of responsibility and management of health-related quality of life".

\section{References}

1. E.P. Belinskaya, A.O. Savinkina, Sociopsychological health problems. Man is working. An interdisciplinary approach in the psychology of health. 7-37. (Moscow, Pero. 2018)

2. E. Giddens, Elusive World: How Globalization Changes Our Lives. (Moscow, The whole world. 2014).

3. N.V. Grishina, Psychological well-being in an existential sense: empirical features. Retrieved from: http://psystudy.ru/index.php/num/2016v9n48/1312grishina48.html (2016).

4. A.I. Gusev, Tolerance of uncertainty as a component of personal potential. Retrieved from: https://www.litmir.me/br/?b=221353\&p=103 (2011).

5. E.A. Evstifeeva, L.A. Murashova, Tver State Medical University. Socio-humanitarian technologies for the diagnosis of quality of life in medical practice. (Tver, 2017).

6. G.M. Zarakovsky, The quality of life of the population of Russia. The psychological components. (Moscow, Smysl. 2009).

7. A.V. Karpov, Psychological Journal, Reflexivity as a mental property and methods of its diagnostics. 24, 5, 45-57. (2003). 
8. T.V. Kornilova, Psychological Journal, New Questionnaire of Tolerance - Intolerance to Uncertainty. 31, 1. 74-86. (2010).

9. A.A. Lebedeva, Journal of the Higher School of Economics, Theoretical approaches and methodological problems of studying the quality of life in the sciences of man. Psychology. 9, 2, 3-19. (2012).

10. V.E. Lepsky, Collection of materials of the International Symposium. Ethical Aspects in V.A. Lefebvre's models in the context of the evolution of ideas about scientific rationality. Reflective processes and management. 43-56 (Moscow: "Kogito Center", 2013).

11. A.A Novik, T.I. Ionova, Guide to the study of the quality of life in medicine. 2nd edition. (Moscow, Media Group, 2007).
12. A.A Novik, S.A Matveev, T.I. Ionova Clinical Medicine, Assessment of the quality of life of a patient in medicine. 2, 10-13. (2000).

13. V.A. Petrovsky, Psychology. Journal of the Higher School of Economics, Consistency and reflection: $a$ model of four resources. 2008, 5, 1, 77-100. (2008).

14. L.A. Sorokina, D.V. Sukhorukov, E.V. Smirnova Health Education, Health-saving technologies in the educational process as a factor in improving the quality of human potential. 1 (29), 111-114. (2013).

15. S.I. Filippchenkova, VNIITE. Psychological model of interaction between a doctor and a patient. Moscow, (2013)

16. V.I. Shamshurin, N.G. Shamshurina, Philosophy of health: historical, philosophical and medical foundations. Man, 1, 101-115. (2018). 